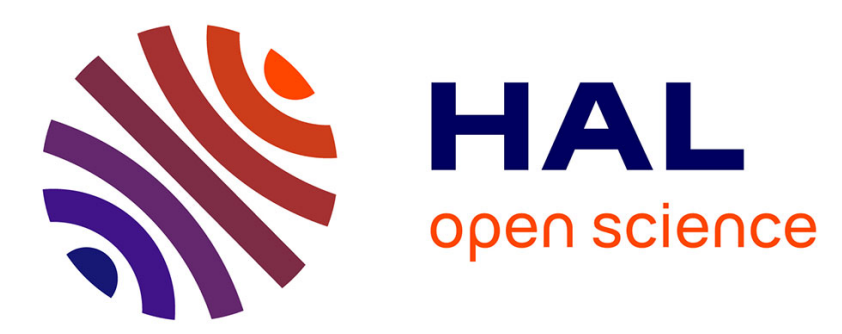

\title{
Fractional order extremum seeking approach for maximum power point tracking of photovoltaic panels
}

Ammar Neçaibia, Samir Ladaci, Abdelfatah Charef, Jean Jacques Loiseau

\section{To cite this version:}

Ammar Neçaibia, Samir Ladaci, Abdelfatah Charef, Jean Jacques Loiseau. Fractional order extremum seeking approach for maximum power point tracking of photovoltaic panels. Frontiers in Energy, 2015, 9 (1), pp.43-53. 10.1007/s11708-014-0343-5 . hal-01713688

\section{HAL Id: hal-01713688 \\ https://hal.science/hal-01713688}

Submitted on 20 Feb 2018

HAL is a multi-disciplinary open access archive for the deposit and dissemination of scientific research documents, whether they are published or not. The documents may come from teaching and research institutions in France or abroad, or from public or private research centers.
L'archive ouverte pluridisciplinaire HAL, est destinée au dépôt et à la diffusion de documents scientifiques de niveau recherche, publiés ou non, émanant des établissements d'enseignement et de recherche français ou étrangers, des laboratoires publics ou privés. 


\title{
Ammar NEÇAIBIA, Samir LADACI, Abdelfattah CHAREF, Jean Jacques LOISEAU \\ Fractional order extremum seeking approach for maximum power point tracking of photovoltaic panels
}

\author{
(C) Higher Education Press and Springer-Verlag Berlin Heidelberg 2014
}

\begin{abstract}
Due to the high interest in renewable energy and diversity of research regarding photovoltaic (PV) array, a great research effort is focusing nowadays on solar power generation and its performance improvement under various weather conditions. In this paper, an integrated framework was proposed, which achieved both maximum power point tracking (MPPT) and minimum ripple signals. The proposed control scheme was based on extremumseeking (ES) combined with fractional order systems (FOS). This auto-tuning strategy was developed to maximize the PV panel output power through the regulation of the voltage input to the $\mathrm{DC} / \mathrm{DC}$ converter in order to lead the PV system steady-state to a stable oscillation behavior around the maximum power point (MPP). It is shown that fractional order operators can improve the plant dynamics with respect to time response and disturbance rejection. The effectiveness of the proposed controller scheme is illustrated with simulations using measured solar radiation data.
\end{abstract}

Keywords extremum seeking (ES), fractional order control (FOC), fractional calculus, photovoltaic (PV)

Received February 20, 2014; accepted June 15, 2014

Ammar NEÇAIBIA

Research Unit in Renewable Energies in the Saharan Medium, CDEREPST, URER-MS, Adrar 01000, Algeria; Department of Electrical Engineering, University of Skikda, Skikda 21000, Algeria

Samir LADACI ( $\bowtie)$

Department of Electronics, Electrotechnics and Automatics, National Polytechnic School of Constantine, Constantine 25000, Algeria; SP-Lab Laboratory, Department of Electronics, University of Constantine 1, Constantine 25000, Algeria

E-mail: samir_ladaci@yahoo.fr

Abdelfattah CHAREF

SP-Lab Laboratory, Department of Electronics, University of Constantine 1, Constantine 25000, Algeria

Jean Jacques LOISEAU

Research Institute in Communications and Cybernetics, CNRS UMR 6597, 1 rue de la Noë 44321 Nantes, France panel, maximum power point tracking (MPPT)

\section{Introduction}

The application fields of fractional calculus are increasingly widening, including areas such as electrical engineering, automation and control engineering, robotics, biomedical engineering and recently the renewable energy domain [1-3]. The main reasons for this growing interest in fractional order operators and systems are their good performances, hereditary properties, and the recent advances in computer science and numerical tools.

Fractional order control (FOC) is one of the fields which has attracted a lot of research efforts, with many encouraging results such as the so-called "commande robuste d'ordre non entier" (in French) CRONE control [4], fractional PID control [5,6], fractional order optimal control [7], fractional adaptive control...etc [8]. Nearly a decade since, particularly in the adaptive control area, many researchers have proposed several fractional adaptive control schemes such as the fractional model reference adaptive control [9], the fractional adaptive high gain control [10], the fractional adaptive sliding mode control [11], and the fractional adaptive internal model control [12].

In this paper, a new fractional adaptive control strategy based on extremum seeking control is applied to optimize the PV cells output power in order to enhance the control system performances. The power generated from the photovoltaic array is delivered to the load through a DC/ DC converter to control the output voltage of the solar panel and achieve a maximum energy extraction. The main purpose of using a DC/DC converter is to make the PV system operate at maximum power point (MPP) located at the knee of the $I-V$ characteristic.

An MPP tracker is also required in order to track the MPP and supply to the controller the appropriate reference input. Many MPP tracking (MPPT) techniques have been proposed to achieve the goal for solar and wind energy 
conversion systems [13-16]; the most widely used MPPT in the literature are called the hill climbing methods, imposing the reference output to the controller and achieving operation at the maximum power conditions. But these methods are incapable of extracting power with the highest efficiency (slow transient response and possible undesirable oscillations around the MPP) [17]. One of the methods proposed, called extremum seeking, has shown some improvement in performances and robustness in experimental tests when compared to the previous solutions [18].

Extremum seeking algorithms have been applied in various research areas related to power energy efficiency [13]. A field in which the extremum seeking technique has proved to be extremely powerful is the maximization of the generated power from PV array.

The main purpose of this paper is to introduce the fractional order technique in the extremum seeking approach which presents several advantages over the conventional control techniques such as easy implementation. It is expected to improve PV system utilization efficiency under rapid and continuous changes in solar radiation overcoming disturbances and uncertainties. The implementation of a PV array MPPT using the fractional order technique achieves these two keys of vital importance.

In this paper, an MPPT by fractional order extremum seeking (FOES) algorithm is proposed. The new algorithm will provide an efficient extraction of the PV array energy and will ensure the stability of the proposed closed-loop control system for abrupt or fast variations of the external conditions.

\section{Basic concepts of fractional order}

\subsection{Fractional derivatives and integrals}

Fractional calculus is a generalization of the integration and differentiation to non-integer-order fundamental operator ${ }_{a} D_{t}^{\mu}$ where $a$ and $t$ are the bounds of the operation. The fractional order differentiator can be presented by a general operator given by

$$
{ }_{a} D_{t}^{\mu}= \begin{cases}\frac{\mathrm{d}^{\mu}}{\mathrm{d} t^{\mu}} & \operatorname{Re}(\mu)>0, \\ 1 & \operatorname{Re}(\mu)=0, \\ \int_{a}^{t}(\mathrm{~d} \tau)^{-\mu} & \operatorname{Re}(\mu)<0,\end{cases}
$$

where $\mu$ is the order of derivative or integral and $\operatorname{Re}(\mu)$ is the real part of $\mu$.

The mathematical definition of fractional derivatives and integrals has been the subject of several descriptions. The three most frequently used definitions for the general fractional differintegral are the Grünwald-Letnikov (GL) definition, the Riemann-Liouville (RL), and the Caputo definition [19-21]. One of the most used definitions of the general fractional integro-differential operator is the RL fractional order. The integral of order is defined as

$$
{ }_{a} D_{t}^{-\mu} f(t)=\frac{1}{\Gamma(\mu)} \int_{a}^{t}(t-\tau)^{\mu-1} f(\tau) \mathrm{d} \tau,
$$

while the definition of fractional-order derivatives is

$$
{ }_{a} D_{t}^{\mu} f(t)=\frac{1}{\Gamma(n-\mu)} \frac{\mathrm{d}^{\eta}}{\mathrm{d} t^{\eta}}\left[\int_{a}^{t} \frac{f(\tau)}{(t-\tau)^{\mu-\eta+1}} \mathrm{~d} \tau\right],
$$

where

$$
\Gamma(x)=\int_{t}^{a} y^{\mu-1} \mathrm{e}^{-y} \mathrm{~d} y,
$$

$\Gamma(\cdot)$ is the Euler's Gamma function, $a$ and $t$ are the limits of the operation, and $\mu$ is the number identifying the fractional order. In this paper, $\mu$ is assumed as a real number that satisfies the restriction $0<\mu<1$. Besides, it is assumed that $a=0$ and the convention ${ }_{a} D_{t}^{\mu}=D^{\mu}$ is used. The other approach is GL definition of fractional order integral, given by

$$
{ }_{a} D_{t}^{-\mu} f(t)=\lim _{h \rightarrow 0} h^{\mu} \sum_{r=0}^{[(t-a) / h]} \frac{\Gamma(\eta-\mu+1)}{r ! \Gamma(\mu)} f(t-r h),
$$

where $[x]$ stands for the greatest integer not exceeding $x$, while the definition of fractional-order derivatives is

$$
{ }_{a} D_{t}^{\mu} f(t)=\lim _{h \rightarrow 0} h^{-\mu} \sum_{r=0}^{[(t-a) / h]}(-1)^{r} \frac{\Gamma(\mu+1)}{r ! \Gamma(\mu-r+1)} f(t-r h),
$$

where the binomial coefficients $(r>0)$ are given by

$$
\left(\begin{array}{l}
\mu \\
0
\end{array}\right)=1,\left(\begin{array}{l}
\mu \\
r
\end{array}\right)=\frac{\mu(\mu-1) \cdots(\mu-r+1)}{r !} .
$$

Many approaches have been proposed to implement fractional order systems (FOS). The numerical simulation of such systems depends on the way to modelize the fractional derivative operator. A first approach consists of discretizing the derivative operator according to the Grünwald method. This technique is very simple to use, but the simulation requires, for each step, the computation of sums of increasing dimension with time. Another approach needs an approximation method in order to obtain an equivalent rational transfer function, by using a specific representation in the frequency domain, and in this paper, the so called singularity function method proposed by Charef et al. [22] is used.

\subsection{Singularity function approximation method}

To implement fractional order operators, an approximation method is needed in order to obtain equivalent rational 
transfer functions. There are many methods both in timedomain and frequency domain. In this paper, the so called singularity function proposed by Charef et al. [22] is used, which is very close to Oustaloup's method [4], allowing the approximation of fractional order transfer function with rational ones. This method is very easy to implement and is based on the approximation of a function of the form

$$
H(s)=s^{\mu}, \mu \in \mathbf{R}^{+}
$$

by a quotient of polynomials in $s$ in a factorized form

$$
\hat{H}(s)=K_{\mathrm{D}} \frac{\prod_{i=0}^{N}\left(1+\frac{s}{z_{i}}\right)}{\prod_{i=0}^{N}\left(1+\frac{s}{p_{i}}\right)} .
$$

Computed on the frequency interval $\omega \in\left[\omega_{\mathrm{b}}, \omega_{\mathrm{h}}\right]$ such that

$$
K_{\mathrm{D}}=\omega_{\mathrm{c}}^{\mu}
$$

where $\omega_{\mathrm{c}}$ is the cutting frequency computed as

$$
\omega_{\mathrm{c}}=\omega_{\mathrm{b}} \sqrt{10^{(\zeta / 10 \mu)-1}}
$$

and the coefficients are computed for obtaining a maximum deviation from the original magnitude response in the frequency domain of $\zeta \mathrm{dB}$. Defining

$$
a=10^{\zeta / 10(1-\mu)}, b=10^{\zeta / 10 \mu}, a b=10^{\zeta / 10(1-\mu)} .
$$

The poles and zeros of the approximated rational function are obtained by applying

$$
z_{0}=\omega_{\mathrm{c}} \sqrt{b}, z_{i}=z_{0}(a b)^{i}, p_{i}=a z_{0}(a b)^{i} .
$$

The number of poles and zeros is related to the desired band-width and the error criteria used by the expression

$$
N=\left[\frac{\ln \left(w_{\max } / p_{0}\right)}{\ln (a b)}\right]+1 \text {. }
$$

\section{Fractional extremum seeking control}

The foundations of extremum-seeking (ES) control returns back to the early 1920s in the work of Leblanc on the search of the resonance peak of an electromechanical system [23]. In the 1960s, there were also important contributions, of which the works of Korovin and Morosanov constitute the most significant advances [23]. The nonlinear and adaptive nature of such control is clearly shown in Ref. [24]. Although there are different ES algorithms, an important analytic effort should be made in order to establish the stability regions of a great number of reported applications [25].

A new robust control scheme for the class of first order linear dynamical systems based on the approach proposed by Carnevale et al. in Ref. [26], called dynamic extremum seeking, is presented to end a reference signal for a dynamical system such that an unknown cost function of its output is minimized or maximized.

The problem of finding the global minimum of a static unknown map $g(\cdot): \mathbf{R} \rightarrow \mathbf{R}$ is addressed whose input is affected by a disturbance $t \mapsto \mathrm{d}(t)$, as shown in Fig. 1 . As is the case in Ref. [26], the map $g(\cdot)$ is assumed to satisfy the following assumptions.

Assumption 1 The unknown map $g(\cdot): \mathbf{R} \rightarrow \mathbf{R}$ is locally Lipschitz and locally bounded.

In the considered extremum seeking synthesis problem, a probing signal $\theta$ is assumed to be exploited, which is constrained to act on the function $g(\cdot)$ through a scalar dynamical system having the simplified form of

$$
\varepsilon \dot{y}=-y+\theta,
$$

where $\varepsilon$ is a positive scalar. The input and the output of the static map $g(\cdot)$ are assumed to be two measurable signals, as represented in Fig. 1, corresponding to

$$
\begin{aligned}
& u_{g}=y(t)+d(t), \\
& y_{g}=g(y(t)+d(t)) .
\end{aligned}
$$

As in the initial integer order control scheme proposed in Ref. [26], there are some boundedness conditions on the disturbance signal $d$ exciting the function $g(\cdot)$ to be fulfilled, as stated in Assumption 2.

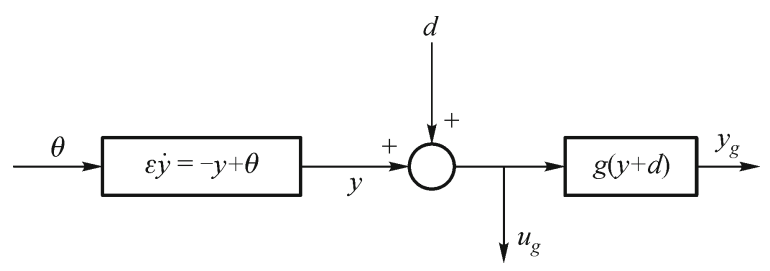

Fig. 1 Block diagram of the scheme under consideration

Assumption 2 The disturbance $d(\cdot)$ is bounded and has a bounded time derivative, namely there exist positive numbers $\bar{d}$ and $\bar{d}_{d}$ such that $|d(t)| \leqslant \bar{d},|\bar{d}| \leqslant \bar{d}_{d}$ for all $t \geqslant 0$.

The control strategy implies also two extremum seeking laws assigning $q$, assuming that the signals in Eq. (11) are available. Moreover, a strong assumption has to be made on the ability to obtain an ideal derivative of the input and the output of the unknown map $g(\cdot)$, i.e. it is assumed that Eq. (12) is known.

$$
\begin{aligned}
& z_{1}(t)=\dot{u}_{g}(t)=\dot{y}(t)+\dot{d}(t), \\
& z_{2}(t)=\dot{y}_{g}(t)=\frac{\partial g(y(t)+d(t))}{\partial y}(\dot{y}(t)+\dot{d}(t)) .
\end{aligned}
$$

It is clear that for actual implementation, approximations of the signals in Eq. (12) will be used. The proposed 
control scheme is obtained by introducing a fractional order integral $1 / s^{\lambda}$ into the initial control scheme of Carnevale et al. in Ref. [26], as represented in Fig. 2. The unknown map is $g(\cdot)$, whose inputs are the output of the first order linear dynamical system $y$ and the disturbance signal $d$.

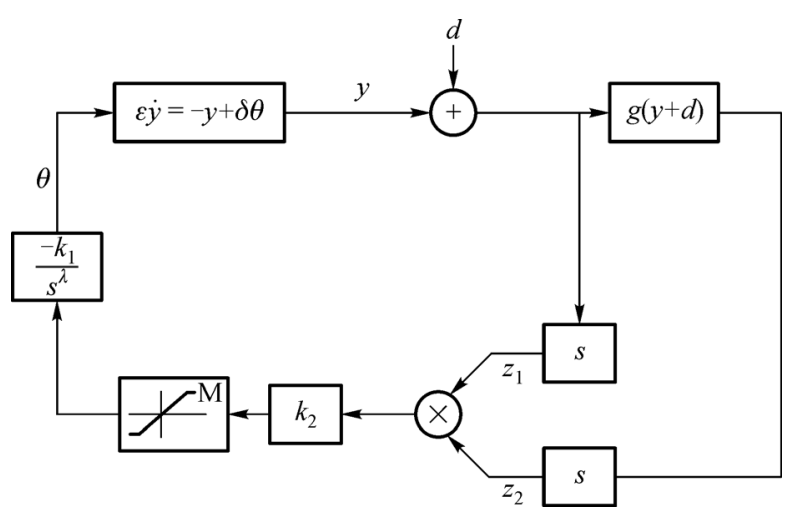

Fig. 2 Dynamical extremum seeking scheme (ESC) using fractional order integration

The parameter $\varepsilon>0$ sets the convergence speed of $y$ to $\delta_{k} \theta$, where $\delta_{k}>0$ is the static gain of the linear plant. The output of a unit saturation is fed with the signal $k_{2} z_{1}(t) z_{2}(t)$ and is integrated by fractional order $1 / \mathrm{s}^{\lambda}$ and multiplied by $k_{1}$, yielding the plant reference $\theta(t)$, with positive scalars $k_{1}$ and $k_{2}$.

Then, $\theta$ is generated by the dynamics presented in Ref. [26]. By introducing FO integration Eq. (13) is obtained.

$$
\frac{\mathrm{d}^{\lambda} \theta}{\mathrm{d} t}=-k_{1} \operatorname{sat}\left(k_{2} z_{1}(t) z_{2}(t)\right),
$$

where $\operatorname{sat}(\cdot)$ is the saturation function, so

$$
s^{\lambda} \theta=-k_{1} \operatorname{sat}\left(k_{2} z_{1}(t) z_{2}(t)\right),
$$

and the control law becomes

$$
\theta=\frac{-k_{1} \operatorname{sat}\left(k_{2} z_{1}(t) z_{2}(t)\right)}{s^{\lambda}},
$$

with $k_{1}>0, k_{2}>0$, and fraction order $0 \leqslant \lambda \leqslant 1$. The block diagram of the corresponding closed-loop system is represented in Fig. 2.

In Refs. [9, 27], it is noticed that the introduction of fractional order integration in adaptation algorithms increases the reference amplitude variation domain where the closed loop stability is maintained. In fact, this stability control objective is better achieved with a sufficiently small regulating parameter $k_{2}$. This is why the adaptive control loop can be stabilized by using fractional order integration where an integer control rule fails.
Remark The selection of $\theta$ as in Eq. (15) guarantees that $\theta \leqslant \frac{k_{1}}{s^{\lambda}}$, an appealing property of the probing signal since it avoids exciting possible high frequency dynamics. Moreover, whenever necessary, the method makes it possible to meet the rate saturation constraints of the physical devices.

\section{Photovoltaic system}

\subsection{Solar module modelization}

The solar PV module is formed by an appropriate seriesparallel combination of solar cells that provides the required rated output voltage and current under normal conditions. A solar cell is basically a P-N junction semiconductor that directly converts solar energy into electricity. The complete structure of a PV cell can be represented by an equivalent circuit model, as illustrated in Fig. 3.

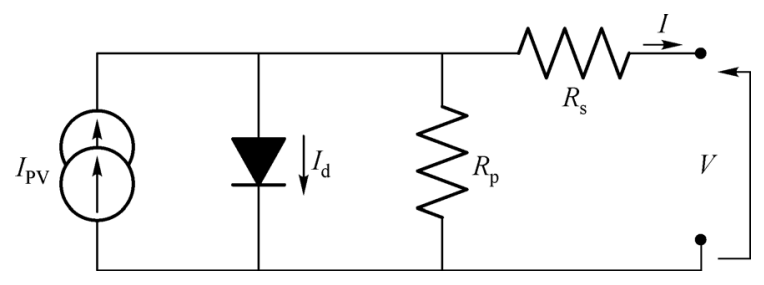

Fig. 3 Equivalent circuit model of PV cell

The solar cell terminal current can be expressed as

$$
I=I_{\mathrm{ph}}-I_{\mathrm{d}}-I_{\mathrm{sh}} \text {. }
$$

The photo-generated current $I_{\mathrm{ph}}$ depends on both irradiation and temperature. It is measured at some reference conditions such as reference temperature $T_{\mathrm{c}, \text { ref }}$, reference radiation $G_{\text {ref }}$ and reference photo current $I_{\text {ph,ref }}$ and related as Eq. (17) in Ref. [28].

$$
I_{\mathrm{ph}}=\frac{G}{G_{\mathrm{ref}}}\left[I_{\mathrm{ph}, \mathrm{ref}}+I_{\mathrm{sc}}\left(T_{\mathrm{c}}-T_{\mathrm{c}, \mathrm{ref}}\right)\right],
$$

where $G$ is the actual solar irradiation $\left(\mathrm{W} / \mathrm{m}^{2}\right) ; T_{\mathrm{c}}$, the actual operating temperature of cell $(\mathrm{K})$; and $I_{\mathrm{sc}}$, the manufactured supplied temperature coefficient of the short circuit current $(\mathrm{A} / \mathrm{K})$. The diode current is given by the Shockley equation

$$
I_{\mathrm{d}}=I_{0}\left[\exp \left(\frac{\mathrm{e}\left(V_{\mathrm{c}}\right)}{\eta \mathrm{K} T_{\mathrm{c}}}\right)-1\right]
$$

where $V_{\mathrm{c}}$ is the voltage across diode $(\mathrm{V}) ; I_{0}$, the reverse saturation current $(\mathrm{A}) ; \eta$, the diode ideality factor; $R_{\mathrm{s}}$, the series resistance $(\Omega)$; e, the electron charge $1.602 \times 10^{-19} \mathrm{C}$; and $\mathrm{K}$, the Boltzmann constant, $1.38 \times 10^{-23} \mathrm{~J} / \mathrm{K}$. The reverse saturation current $I_{0}$ is 
given by Eq. (19) in Ref. [28].

$$
I_{0}=I_{0, \text { ref }}\left(\frac{T_{\mathrm{c}}}{T_{\mathrm{c}, \text { ref }}}\right)^{3} \exp \left[\left(\frac{e E_{\mathrm{g}}}{\eta k}\right)\left(\frac{1}{T_{\mathrm{c}, \text { ref }}}-\frac{1}{T_{\mathrm{c}}}\right)\right] .
$$

The shunt current $I_{\text {sh }}$ is given by

$$
I_{\mathrm{sh}}=\frac{V+I R_{\mathrm{s}}}{R_{\mathrm{p}}}
$$

where $R_{\mathrm{p}}$ is the shunt resistance $(\Omega)$. The PV module power can be computed using $P=I V$. The power-voltage $(P-V)$ and the current-voltage $(I-V)$ characteristic curves of the PV array are nonlinear, as depicted in Fig. 4. Figure 5 presents the PV panel characteristic curves under weather conditions.

\section{2 $\mathrm{DC} / \mathrm{DC}$ converter model}

The problem of MPPT is employed to control the input voltage and the duty cycle of the boost converter $(\mathrm{DC}=\mathrm{DC}$ or $\mathrm{DC}=\mathrm{AC}$ converter) where the $\mathrm{PV}$ module delivers maximum power. This removes the mismatch between the load and maximum power operating point of the PV module. The basic configuration of the boost converter is displayed in Fig. 6 [29]. When the switch is in the "off" state, the solar energy is transferred to the output storage capacitor by the boost inductance. Varying the duty of switching time can regulate the input voltage and current. During the turn-off time $t_{\text {off }}$ and turn-on time $t_{\text {on }}$, the

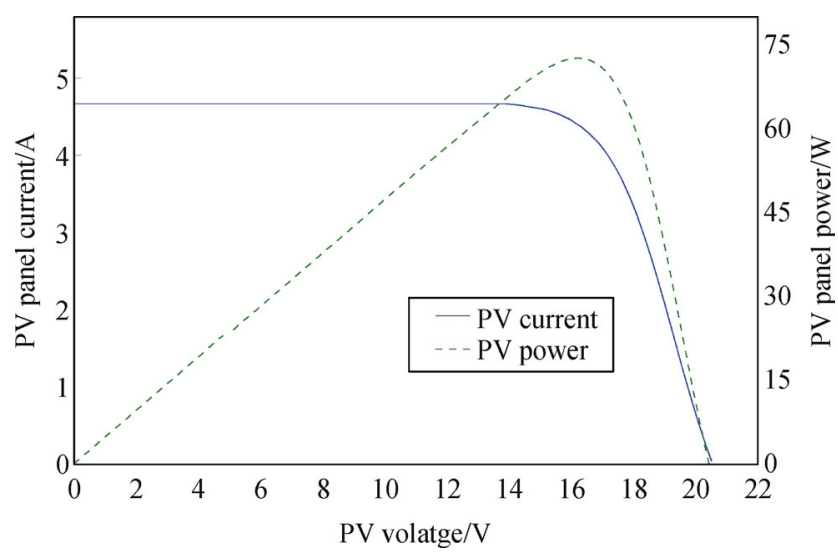

Fig. $4 \quad P-V$ and the $I-V$ characteristic of PV array

current flow in the inductance $L$ can be expressed in Eq. (21), as in the case in Ref. [30].

$$
\left\{\begin{array}{l}
\text { Turn-off duration: } I_{\max }-I_{\min }=\left(\frac{V_{\mathrm{o}}-V_{\mathrm{i}}}{L}\right) t_{\mathrm{off}}, \\
\text { Turn-onduration: } I_{\max }-I_{\min }=\left(\frac{V_{\mathrm{i}}}{L}\right) t_{\mathrm{on}} .
\end{array}\right.
$$

The duty cycle of the control signal is defined as

$$
D=\frac{T_{\text {on }}}{t_{\text {on }}-t_{\text {off }}} \text {. }
$$
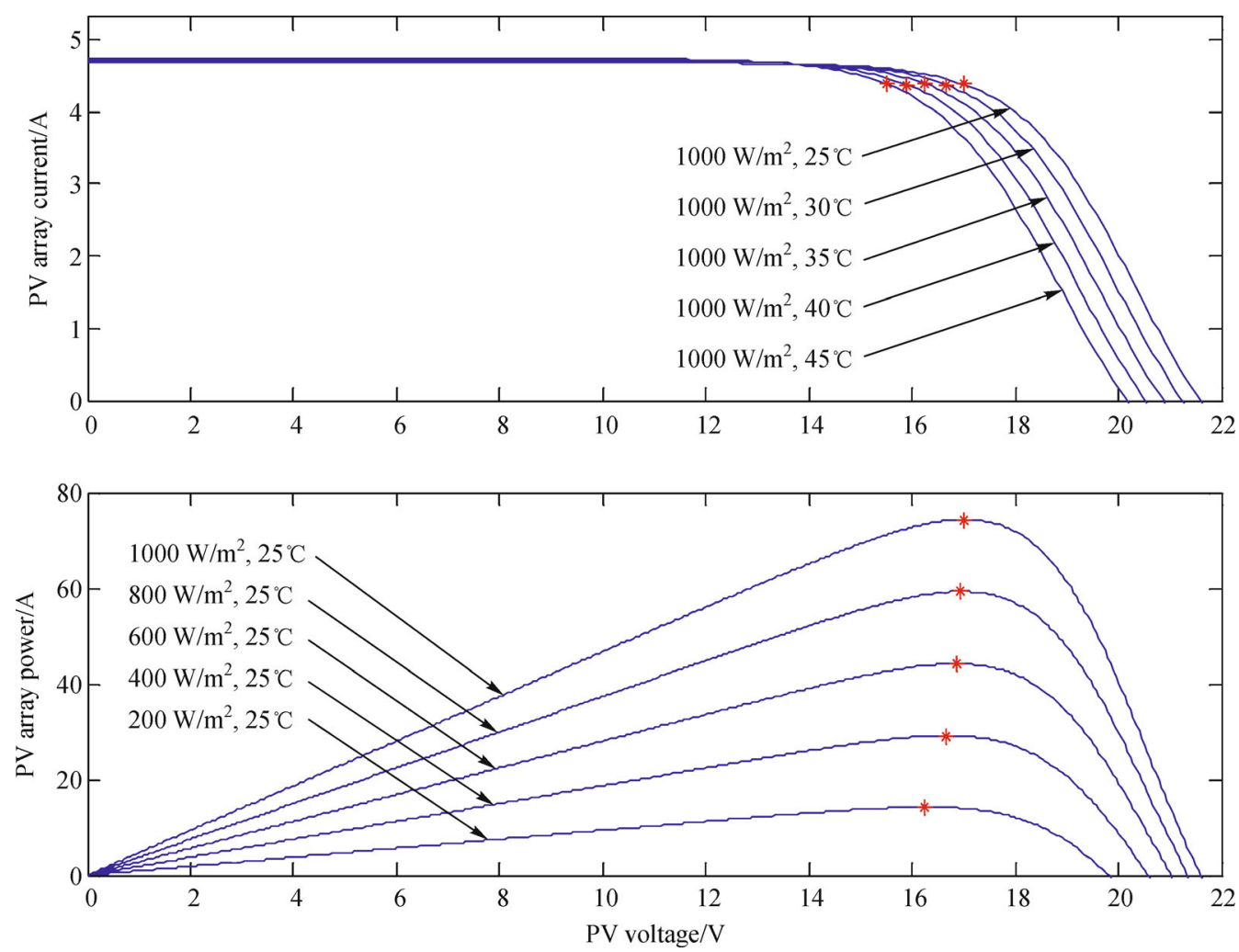

Fig. 5 Effects of ambient temperature and irradiation variations on $I-V$ and $P-V$ 


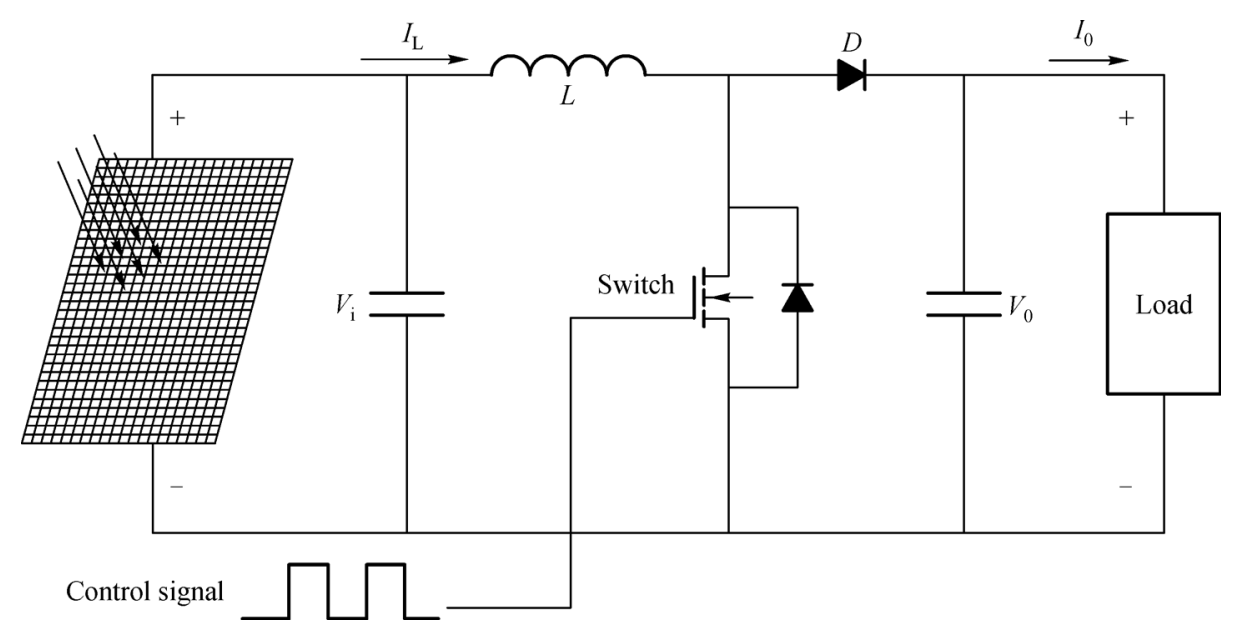

Fig. 6 Basic configuration of boost converter

By eliminating the difference $I_{\max }-I_{\min }$, the output voltage $V_{\mathrm{o}}$ can be expressed as

$$
V_{\mathrm{o}}=V_{\mathrm{i}}\left(\frac{t_{\mathrm{on}}+t_{\mathrm{off}}}{t_{\mathrm{off}}}\right)=\frac{V_{\mathrm{i}}}{1-D} .
$$

\subsection{Application of FOES to PV array}

The overall system, as exhibited in Fig. 7, mainly consists of the PV panel, which generates power directly from solar radiation, and the boost converter, whose switch is operated by the proposed fractional order extremum seeking control scheme.

Due to the fact that the first priority of the boost converter control is MPPT, the control strategy in this paper is based on the DC step-up converter boosting the PV system output voltage, as well as maximizing the power exploitation. The output voltage and current measurements of the PV system are formed as inputs for the FOES algorithm as an unknown function $g(y)=P=I V$.

\subsection{Results and discussion}

The photovoltaic system shown in Fig. 7 consists of a
75 W PV panel whose specifications are given in Tables 1 and 2; whereas the control scheme parameters are represented in Table 3. The system is simulated using the Matlab/Simulink software as represented in Fig. 8.

The proposed method is implemented in the software environment as a controller and the obtained results of the proposed control system are compared to the ones of the control system with the conventional method.

Figure 9 shows the output power of the simulated PV panel whose model is given by Eqs. (16)-(20) for different values of the fractional order $\lambda$ using the proposed fractional order extremum seeking control scheme shown in Fig. 2.

From Fig. 9, it can easily be seen that the integral action fractional order $\lambda$ has an impact on the performances of the proposed FOES control strategy in terms of the convergence rate of the MPPT for the same conditions of temperature and insolation. It can also be noted the substantial improvement is made in the power response for different values of the integral action fractional order compared to the classical case when $\lambda=1$. Another remarkable advantage of the proposed FOES strategy is that the power output $P_{\mathrm{PV}}$ is maintained at its optimal value after the convergence phase for practically all the fractional order values as it can be seen in Fig. 9.

To get the best integral action fractional order $\lambda$ in terms

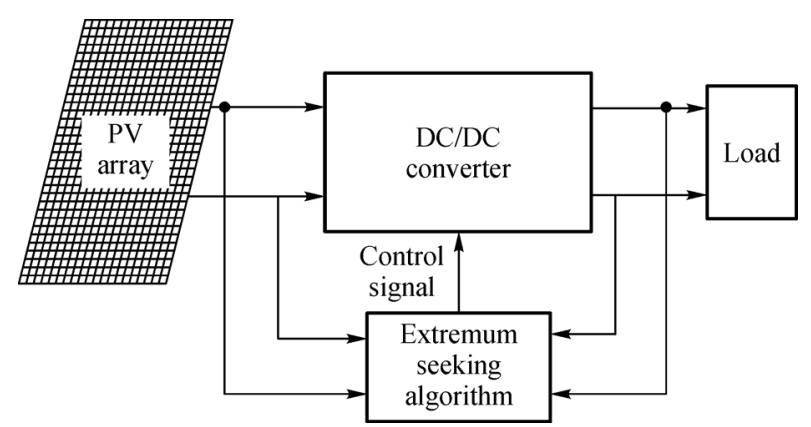

Fig. 7 Overall system: PV panel, boost converter, FOES controller and load 
Table 1 Electrical characteristics data of PV module ISOFOTON 75I-

12 , taken from the data-sheet

\begin{tabular}{lc}
\hline Specification parameter & Value \\
\hline Maximum power $\left(P_{\max }\right)$ & $(75 \pm 7.5 \%) \mathrm{W}$ \\
Maximum power voltage $\left(V_{\mathrm{MPP}}\right)$ & $17.3 \mathrm{~V}$ \\
Maximum power current $\left(I_{\mathrm{MPP}}\right)$ & $4.34 \mathrm{~A}$ \\
Open circuit voltage $\left(V_{\mathrm{oc}}\right)$ & $21.6 \mathrm{~V}$ \\
Short circuit current $\left(I_{\mathrm{oc}}\right)$ & $4.67 \mathrm{~A}$ \\
Temperature coefficient of $I_{\mathrm{sc}}\left(T_{I \mathrm{sc}}\right)$ & $(0.065 \pm 0.015) \% /{ }^{\circ} \mathrm{C}$ \\
Temperature coefficient of $V_{\mathrm{oc}}\left(T_{V \mathrm{oc}}\right)$ & $(-160 \pm 20) \mathrm{mV} /{ }^{\circ} \mathrm{C}$ \\
Panel efficiency $\left(\eta_{\mathrm{PV}}\right)$ & $11.2 \%$ \\
Nominal operating cell temperature $(\mathrm{NOCT})$ & $(47 \pm 2){ }^{\circ} \mathrm{C}$ \\
\hline
\end{tabular}

Table 2 Model parameters of PV module ISOFOTON 75I-12

\begin{tabular}{lcc}
\hline Parameter & Description & Value \\
\hline$n_{\text {cell }}$ & Number of PV cells arranged in series & 36 \\
$R_{\mathrm{s}}$ & Series resistance & $0.24 \Omega$ \\
$R_{\mathrm{p}}$ & Parallel resistance & $670 \Omega$ \\
$\eta$ & Ideality factor & 1.2 \\
\hline
\end{tabular}

Table 3 Extremum seeking parameters

\begin{tabular}{lcc}
\hline Parameter & Description & Value \\
\hline$K_{1}$ & Gradient update law gain1 & 4 \\
$K_{2}$ & Gradient update law gain 2 & 4 \\
$M$ & Min/Max saturation & 0.2 \\
\hline
\end{tabular}

of error minimization between the power output $y$ and the maximal power value $y_{\mathrm{m}}$, the quadratic error criteria given by

$$
J_{\lambda}=\sum_{k=0}^{N_{\omega}}\left(y(k \Delta)-y_{\mathrm{m}}(k \Delta)\right)^{2}
$$

is calculated when $\lambda$ is varied from 0.3 to 1 ; where $N_{\omega}$ is the width of the working time window and $\Delta$ is the time sampling rate. Figure 10 shows the plot of the quadratic error $J_{\lambda}$ as a function of the fractional order $\lambda$. It can be noted from Fig. 10 that the smallest quadratic error corresponds to the parameter $\lambda=0.76$.

For the particular fractional parameter value $\lambda=0.76$ in the proposed FOES control scheme, the MPP tracker converges in approximately $0.015 \mathrm{~s}$; whereas for the

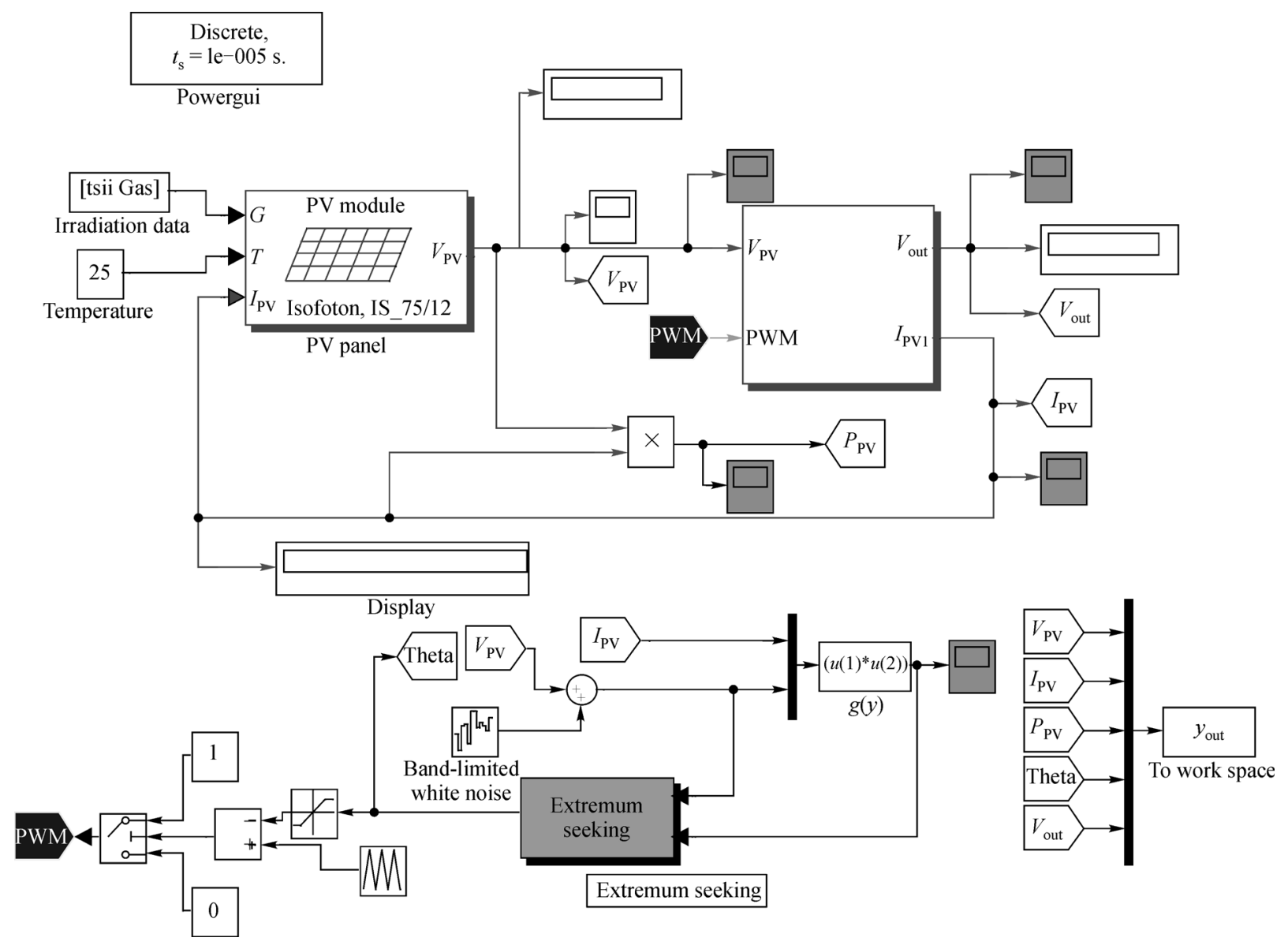

Fig. 8 Overall system presentation in Matlab/Simulink 


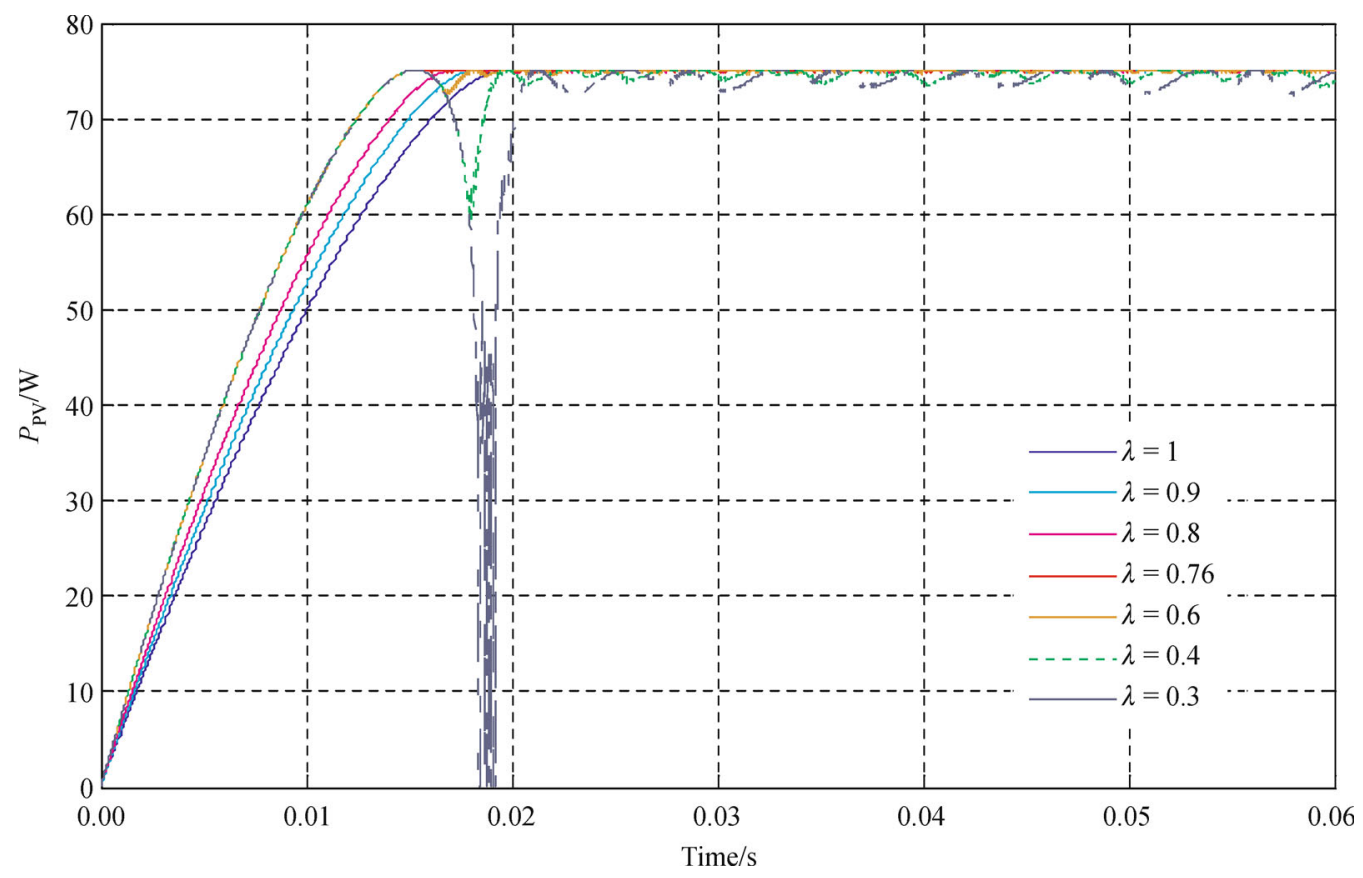

Fig. 9 Power output (W) of PV panel for different values of fractional order $\lambda$

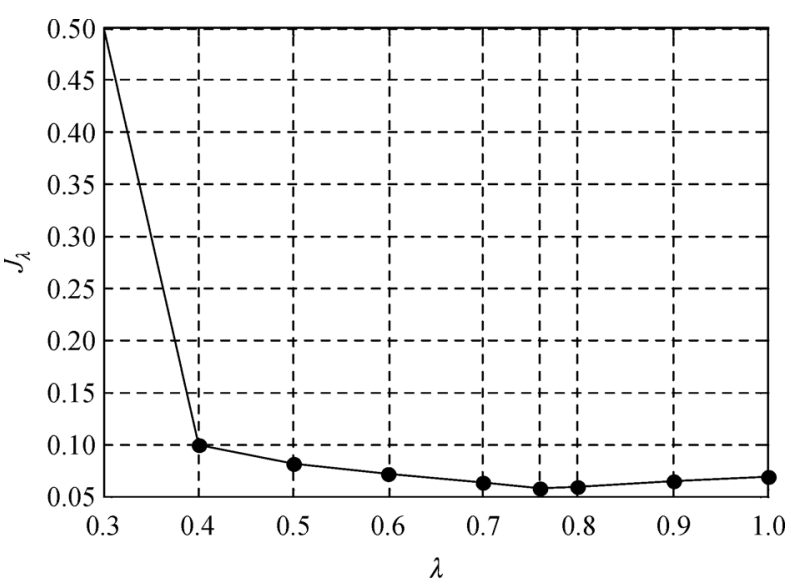

Fig. 10 Quadratic error criteria versus the fractional order $\lambda$

modified integer order ESC-based controller in Ref. [31], the MPP tracker convergence time is about $0.03 \mathrm{~s}$, as illustrated in Fig. 11.

It can be noted that for most of the existing classical ESC-based approaches (see for instance Refs. [31, 32].) the attenuation of the drop occurs when the MPPT system starts, but this attenuation is largely improved with the FOES technique for most of the fractional order parameter $\lambda$ and completely eliminated for some other values such as $\lambda=0.76$, as shown in Fig. 12.

This fact illustrates the robustness of the proposed FOC strategy compared to the conventional ones. However the drop of the power in Fig. 9 occurs for only small values of the fractional order $\lambda(\lambda=0.3)$ which is caused by the small integral action fractional order in the FOES scheme.
The main result and contribution of the proposed FOES approach is to improve the response time and robustness of the power output of the PV panel in the presence of disturbance due to variation of environmental conditions and measurement noises for some real order integral action in the ES control scheme presented in Fig. 2. Indeed, this advantageous robustness enhancement is mainly resulted from the fact that the FOS and operators are long memory processes acting as efficient filters against additive disturbances and noises [33]. The proposed FOES algorithm is also able to reduce the control gain and oscillations around the MPP.

Response to an experimental irradiance scenario: to show the effectiveness of the proposed FOESC-based MPPT in rapidly varying irradiance conditions, its response to a one-day experimental irradiance data has been considered, as shown in Fig. 13. These data were measured on a rooftop of the meteor station at research unit (URERMS) Adrar, Algeria. Two cases in this scenario have been considered. In the first case, the irradiance is almost constant around the specific value of $930\left(\mathrm{~W} / \mathrm{m}^{2}\right)$, and in the second one the irradiance is changing rapidly. Figure 14 provides a detailed view of $30 \mathrm{~min}$ irradiance data of the second case between 13:22 to 13:52 AM, on February 23rd, 2011. This short time range is chosen because it includes rapid irradiance changes which makes it possible to see the controller response to this input.

Figure 15 shows the MPPT results for different values of fractional order 1 , for the fixed scenario irradiance entry. The FOES method accurately tracks the MPP and rises to the MPP orders of magnitude more rapidly than the conventional ES approach $(\lambda=1)$. Figure 16 illustrates the 

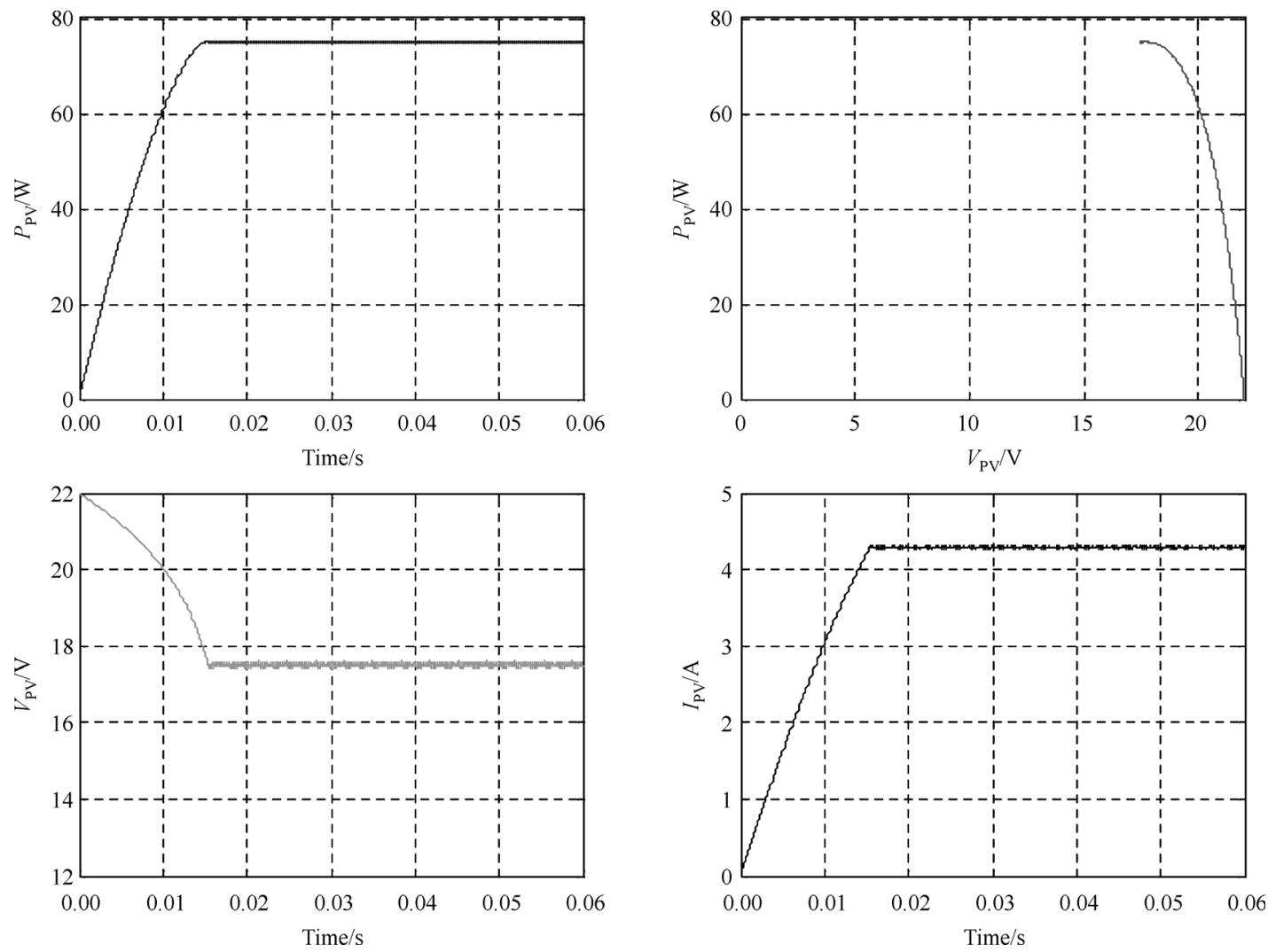

Fig. 11 Outputs of PV panel for "optimal" fractional order value $\lambda=0.76$
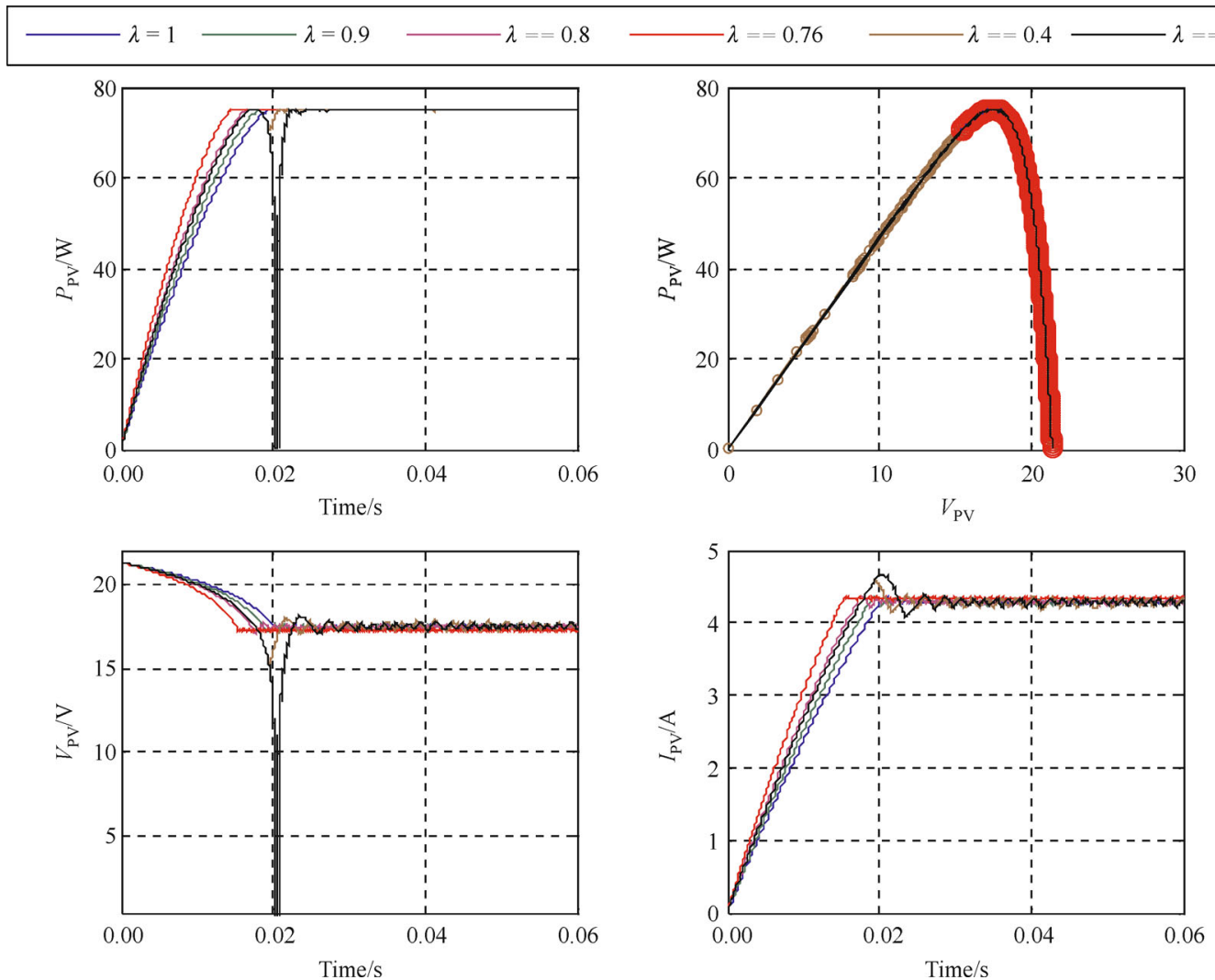

Fig. 12 PV panel outputs for different values of fractional order $\lambda$ 


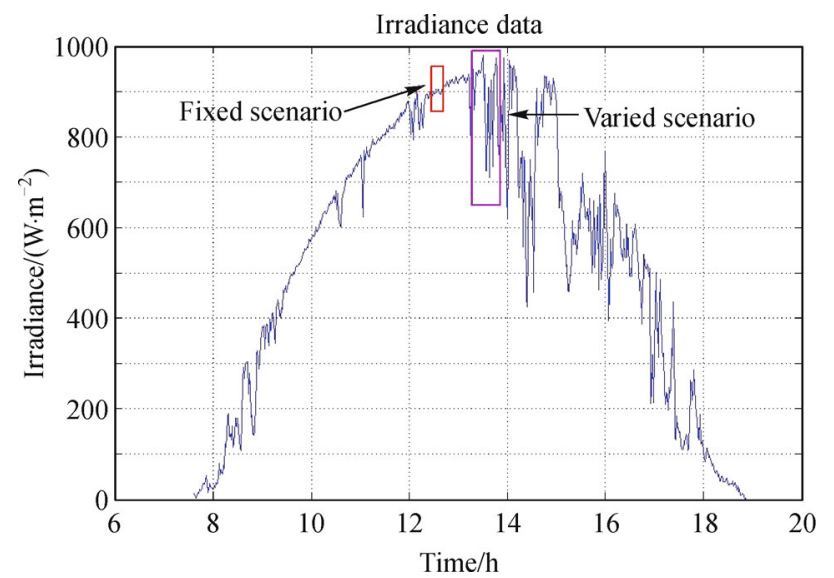

Fig. 13 Irradiance data for one day in February at URERMS research unit

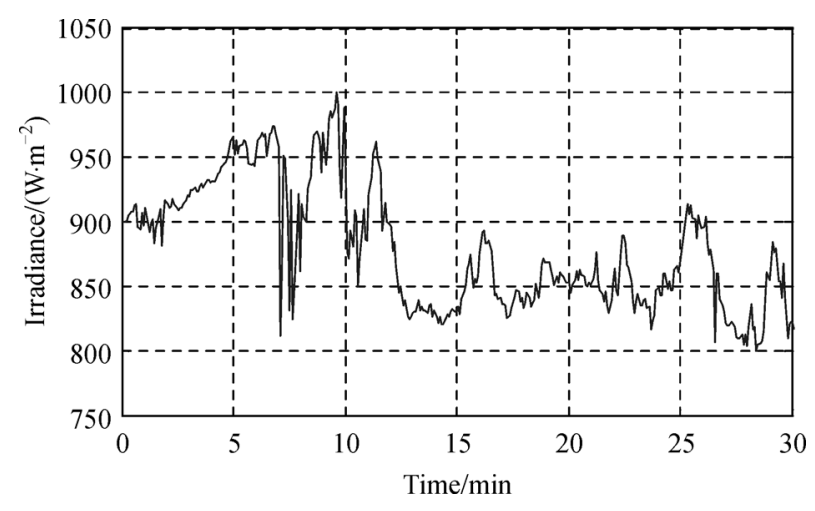

Fig. 14 Irradiance data spanning $30 \mathrm{~min}$ from 13:22 to 13:52 A.M. on February 23rd, 2011

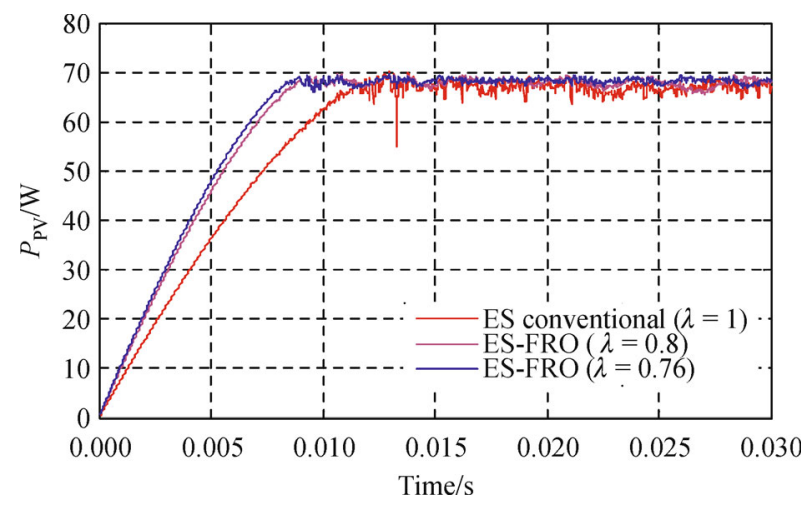

Fig. 15 Proposed fractional order ESC-based MPPT response to fixed scenario $\left(P_{\mathrm{PV}}(\mathrm{W})\right)$

proposed MPP tracking approach response for the varying irradiance scenario case. The fractional order extremum seeking controller tracks the MPP with better performance than the conventional ES approach despite the fast

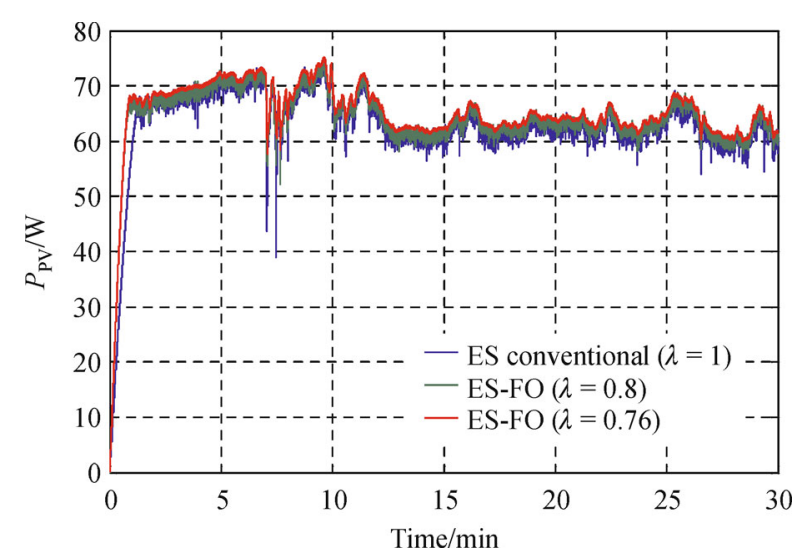

Fig. 16 Proposed fractional order ESC-based MPPT response to varying scenarios

irradiance data variation.

It can be seen that the choice of this fractional order $\lambda$ is critical in the proposed approach as has been remarked that very similar values of $\lambda$ lead to clearly different behaviors (worse than the "optimal" result of $\lambda=0.76$ in simulation results, regarding the time convergence and stability at the desired power maximum). This fact is an important advantage of the proposed FOES controller, which does not depend on the parameters of the PV system (considered as an unknown function as specified in subsection 4.3) but on the real value of the integrator fractional order $\lambda$ in the control scheme, offering a new adjustment parameter and a supplementary degree of freedom for the improvement of the conventional ES-based MPPT performance.

\section{Conclusions}

This paper presents a novel FO-based ES control scheme that is able to reach the optimal MPP, and to maintain the power at this maximum online. We show that the FOES algorithm converges to the global optima faster than the traditional (integer order) approach. Introducing FO operator to ES serves to improve the regulation of the plant outputs in approaching the optimal point.

The parameters of the proposed FOES algorithm are self-tuned, so that the control system becomes able to reduce the control gain and the oscillation level around the MPP, thus improving the robustness and efficiency of the ES control scheme.

Numerical simulation results show the effectiveness of the scheme in finding the global optima successfully in various cases. The proposed FO-ES control scheme is superior to the conventional ES one because it offers a supplementary tuning parameter which is the fractional order operator, enabling more behavior performance and robustness against disturbances and noise. 


\section{References}

1. Lin C H, Huang C H, Du Y C, Chen J L. Maximum photovoltaic power tracking for the PV array using the fractional-order incremental conductance method. Applied Energy, 2011, 88(12): 4840-4847

2. MelícioR, Mendes V M F, Catalao J P S. Fractional-order control and simulation of wind energy systems with PMSG/full-power converter topology. Energy Conversion and Management, 2010, 51 (6): 1250-1258

3. Neçaibia A, Ladaci S. Fractional control based integration of MPPT for photovoltaic arrays. In: The First International Conference on Electrical Engineering and Control Applications, ICEECA'2012, Khenchela, 2012

4. Oustaloup A. La Commande CRONE: Commande Robuste D'ordre Non Entier. Paris: Hermes, 1991 (in French)

5. Podlubny I. Fractional-order systems and $\mathrm{PI}^{\lambda} \mathrm{D}^{\mu}$-controllers. IEEE Transactions on Automatic Control, 1999, 44(1): 208-214

6. Pan I, Das S. Frequency domain design of fractional order PID controller for AVR system using chaotic multi-objective optimization. International Journal of Electrical Power \& Energy Systems, 2013, 51: 106-118

7. Agrawal O P. A general formulation and solution scheme for fractional optimal control problems. Nonlinear Dynamics, 2004, 38 (1-4): 323-337

8. Ladaci S, Charef A. Fractional order adaptive control systems: a survey. In: Mitchell E W, Murray S R eds. Classification and Application of Fractals. Nova Science Publishers Inc., 2012, 261275

9. Vinagre B M, Petras I, Podlubny I, Chen Y Q. Using fractional order adjustment rules and fractional order reference models in model reference adaptive control. Nonlinear Dynamics, 2002, 29(1-4): 269-279

10. Ladaci S, Loiseau J J, Charef A. Fractional order adaptive high gain controllers for a class of linear systems. Communications in Nonlinear Science and Numerical Simulation, 2008, 13(4): 707-714

11. Efe M O, Kasnakoglu C. A fractional adaptation law for sliding mode control. International Journal of Adaptive Control and Signal Processing, 2008, 22(10): 968-986

12. Ladaci S, Loiseau J J, Charef A. Adaptive internal model control with fractional order parameter. International Journal of Adaptive Control and Signal Processing, 2010, 24(11): 944-960

13. Salas V, Olías E, Barrado A, Lázaro A. Review of the maximum power point tracking algorithms for stand-alone photovoltaic systems. Solar Energy Materials and Solar Cells, 2006, 90(11): $1555-1578$

14. Ramaprabha R, Balaji M, Mathur B L. Maximum power point tracking of partially shaded solar PV system using modified Fibonacci search method with fuzzy controller. International Journal of Electrical Power \& Energy Systems, 2012, 43(1): 754-765

15. Ghassami A A, Sadeghzadeh S M, Soleimani A. A high performance maximum power point tracker for PV systems. International Journal of Electrical Power \& Energy Systems, 2013, 53: 237-243
16. Hong $\mathrm{C} \mathrm{M}$, Chen $\mathrm{C} \mathrm{H}$. Intelligent control of a grid-connected windphotovoltaic hybrid power systems. International Journal of Electrical Power \& Energy Systems, 2014, 55: 554-561

17. Houssamo I, Locment F, Sechilariu M. Experimental analysis of impact of MPPT methods on energy efficiency for photovoltaic power systems. International Journal of Electrical Power \& Energy Systems, 2013, 46: 98-107

18. Armstrong S, Hurley W G. A new methodology to optimise solar energy extraction under cloudy conditions. Renewable Energy, 2010, 35(4): 780-787

19. Oldham K B, Spanier J. The Fractional Calculus. New York: Academic Press, 1974

20. Miller K S, Ross B. An Introduction to the Fractional Calculus and Fractional Differential Equations. New York: Wiley Interscience, 1993

21. Podlubny I. Fractional Differential Equations. New York: Academic Press, 1999

22. Charef A, Sun H H, Tsao Y Y, Onaral B. Fractional system as represented by singularity function. IEEE Transactions on Automatic Control, 1992, 37(9): 1465-1470

23. Ariyur K B, Krstic M. Real-Time Optimization by ExtremumSeeking Control. New York: Wiley, 2003

24. Krstić M. Performance improvement and limitation in extremum seeking control. Systems \& Control Letters, 2000, 39(5): 313-326

25. Astrom K J, Wittenmark B. Adaptive Control. 2nd ed. Reading, MA: Addison-Wesley, 1995

26. Carnevale D, Astolfi A, Centioli C, Podda S, Vitale V, Zaccarian L. A new extremum seeking technique and its application to maximize RF heating on FTU. Fusion Engineering and Design, 2009, 84(2-6): 554-558

27. Ladaci S, Charef A. MIT adaptive rule with fractional integration. In: Proceedings of CESA'2003 IMACS Multiconference Computational Engineering in Systems Applications, Lille, 2003

28. Chenni R, Makhlouf M, Kerbache T, Bouzid A. A detailed modeling method for photovoltaic cell. Energy, 2007, 32(9): 17241730

29. Femia N, Petrone G, Spagnuolo G, Vitelli M. Optimization of perturb and observe maximum power point tracking method. IEEE Transactions on Power Electronics, 2005, 20(4): 963-973

30. Kwon J M, Nam K H, Kwon B H. Photovoltaic power conditioning system with line connection. IEEE Transactions on Industrial Electronics, 2006, 53(4): 1048-1054

31. Heydari-doostabad H, Keypour R, Khalghani M R, Khooban M H. A new approach in MPPT for photovoltaic array based on extremum seeking control under uniform and non-uniform irradiances. Solar Energy, 2013, 94: 28-36

32. Lei P, Li Y, Seem J E. Sequential ESC-based global MPPT control for photovoltaic array with variable shading. IEEE Transactions on Sustainable Energy, 2011, 2(3): 348-358

33. Ladaci S, Bensafia Y. Fractionalization: a new tool for robust adaptive control of noisy plants. In: Proceedings of the 6th Workshop on Fractional Differentiation and Its Applications part of IFAC Joint Conference: 5th Symposium on System Structure and Control, 11th Work-shop on Time-Delay Systems. Grenoble, 2013: 379-384 